\title{
Fake News Case Study during the Australian 2019 General Election
}

\author{
Matthew Warren \\ RMIT University Centre for Cyber Security Research and Innovation \\ RMIT University, \\ Melbourne, \\ Australia. \\ matthew.warren2@rmit.edu.au
}

\section{Abstract}

Social media is used by all aspects of society from citizens to businesses, but it also now used by political parties. Political parties use social media to engage with voters as a method of attract new voters or reinforcing the views of political parties' current supporters. An important consideration is the ethical conduct of political parties and politicians in how they use social media. It is now recognized that social media can also have negative aspects seen by the introduction of Fake News. These negative aspects of social media are often overlooked and have not been explored from a research perspective. This paper looks at the Australian 2019 General Election and discusses a major Fake News example that occurred during that election. The paper will also describe the different types of social media data was collected during the study and also present the analysis of the data collected as well discussing the research findings including the ethical issues.

Keywords: Australia; Election; 2019; Fake news; Social media.

\section{Introduction}

Social media has been defined as "a group of Internet based applications that build on the ideological and technological foundations of Web 2.0, and that allow the creation and exchange of user-generated content" (Kaplan \& Haenlein, 2010). Social media impacts all aspects of society from citizens to businesses but also political parties. Social media offers real challenges for political parties as there is an increased acceptance of social media by voters. It also means that political discussions are conducted in a public forum and voters have the ability to contribute to the discussion. This means that political parties may have little control over the discussion or even lose control of the discussion that occur online. The means that social media has real challenges for political parties. So why is social media so important for political parties. It is important because of the large and rapidly increasing number of users (voters) using social media and their increased online expectations. It is also important because users (voters) have expectation around the use of technology to engage with a variety of political organisations and individuals, social media has become the accepted standard due to its of widespread use and ease of use, there is the expectation that users (voters) can engage with political parties via this medium.

From a political party perspective, social media provides a cost-effective medium to reach-out to large number of users (voters), it provides a rich two-way engagement with users (voters) and by its nature creates interaction. Social media also offers business benefits for political parties, by using social media they could engage with many more users (voters) rather than using traditional media, so it means their investment in social media could give greater 
returns. Another key aspect of the use of social media by political parties is that it allows them to influence voters and the way they could vote; this is also known as information operations. Information operations also known as influence operations, includes the collection of tactical information about an adversary as well as the dissemination of propaganda in pursuit of a competitive advantage over an opponent (Waltzman, 2017).

As Thompson (2019) states political ethics is the practice of making moral judgments about political action it is divided into two branches: the ethics of process, which focuses on public officials, the methods they use, and the institutions in which they act; and the ethics of policy, which concentrates on judgments about the policies and laws governments make. A key issue for individual politicians and political parties is whether they also focus on making judgements in an ethical manner and how they interact and use of social media as part of their engagement strategy.

On the 11th April 2019 the Australian Government called for a national election to elect the 46th Parliament of Australia with an election date set for the 18th May 2019 (ABC, 2019). But during the 2019 Australian election a big unknown was whether there would be examples of Fake News and what impact these would cause have upon the Australian election and its outcome.

\section{Literature Review}

The Australian Government was concerned about the impact of political interference in the 2019 Australian General Election. Prior to the July 2018 federal by-elections held across four states in Australia, the Australian Government established a multi-agency body, the Electoral Integrity Assurance Taskforce, to address risks to the integrity of the electoral system particularly in relation to cyber interference and to protect Australia (Buckmaster and Wils, 2019).

Propaganda is information or ideas that are spread by an organised group or government to influence people's opinions, especially by not giving all the facts or by secretly emphasizing only one way of looking at the facts (Sample et al, 2018). Historically propaganda and deception has had a long history associated with warfare (Taylor 2013); however, in the past, the distribution or reach of propaganda was limited (Crilley 2001) by the media (e.g., personto-person, newspapers and other printed materials, radio, and television), therefore it was less effective due to speed and cost. But with the development of Social Media we have seen the ability to share to information at limited costs to a global audience in real time, this has resulted in the development of the concept of Fake News. There is no clear definition of what Fake News is, but a recent UK Parliamentary interim report on Fake News (UK Parliament, 2018) defined some of the key criteria that could be used to describe Fake News, the criteria defined was:

- Fabricated content: completely false content;

- Manipulated content: distortion of genuine information or imagery, for example a headline that is made more sensationalist, often popularised by 'clickbait';

- Imposter content: impersonation of genuine sources, for example by using the branding of an established news agency;

- $\quad$ Misleading content: misleading use of information, for example by presenting comment as fact; 
- $\quad$ False context of connection: factually accurate content that is shared with false contextual information, for example when a headline of an article does not reflect the content;

- $\quad$ Satire and parody: presenting humorous but false stores as if they are true. Although not usually categorised as Fake News, this may unintentionally fool readers.

The final UK Parliamentary Report on Fake News (UK Parliament, 2019) came up with some different findings. The final report proposed that the UK Government accepted the view that the term 'Fake News' is misleading, and the following terms should be used instead 'disinformation' and 'misinformation'. The final UK Parliamentary Report (UK Parliament, 2019) defined the key terms as being, disinformation as the deliberate creation and sharing of false and/or manipulated information that is intended to deceive and mislead audiences, either for the purposes of causing harm, or for political, personal or financial gain and 'Misinformation' refers to the inadvertent sharing of false information.

Some of the other key terms in relation to the negative use of social media include:

- Information Operations (now often called Cyber Operations) - Cyber operations are the means possessing the resources, skills, knowledge, operational concepts and procedures to be able to have an effect in cyberspace. (ASPI, 2018);

- $\quad$ Influence Operations - The collection of tactical information about an adversary as well as the dissemination of propaganda in pursuit of a competitive advantage over an opponent. (Waltzman, 2017);

- $\quad$ Fake News - The malicious publication, dissemination and reproduction, by whatever means, of false news and documents which have been fabricated or falsified or mendaciously attributed to third parties. (French Government, 2018).

\section{Research Question}

The author had identified one key research question for the study. The research question was "Was there any occurrence of Fake News during the Australian General Election in 2019?".

\section{Research}

The aim of the research was to monitor social media during the Australian Election to determine instances of Fake News and the sources of those Fake News stories. During the election there was one major incident identified by the author regarding Fake News. The incident related to Death Tax and the story originated with a media release prior to the 2019 Australian General Election. On the 24th January, 2019 the Australian treasurer, Josh Frydenberg released a media statement online (Frydeberg, 2019) (see Figure 1), stating “Facing growing pressure over Labor's disastrous housing and retirees taxes, Bill Shorten today sought to deflect attention by flippantly remarking that the next thing they say will be "that Labor wants to introduce death taxes". The accusation was that Labor, and the Greens have signed a secret agreement to introduce a 40 per cent "death tax" (Sydney Morning Herald, 2019a). 

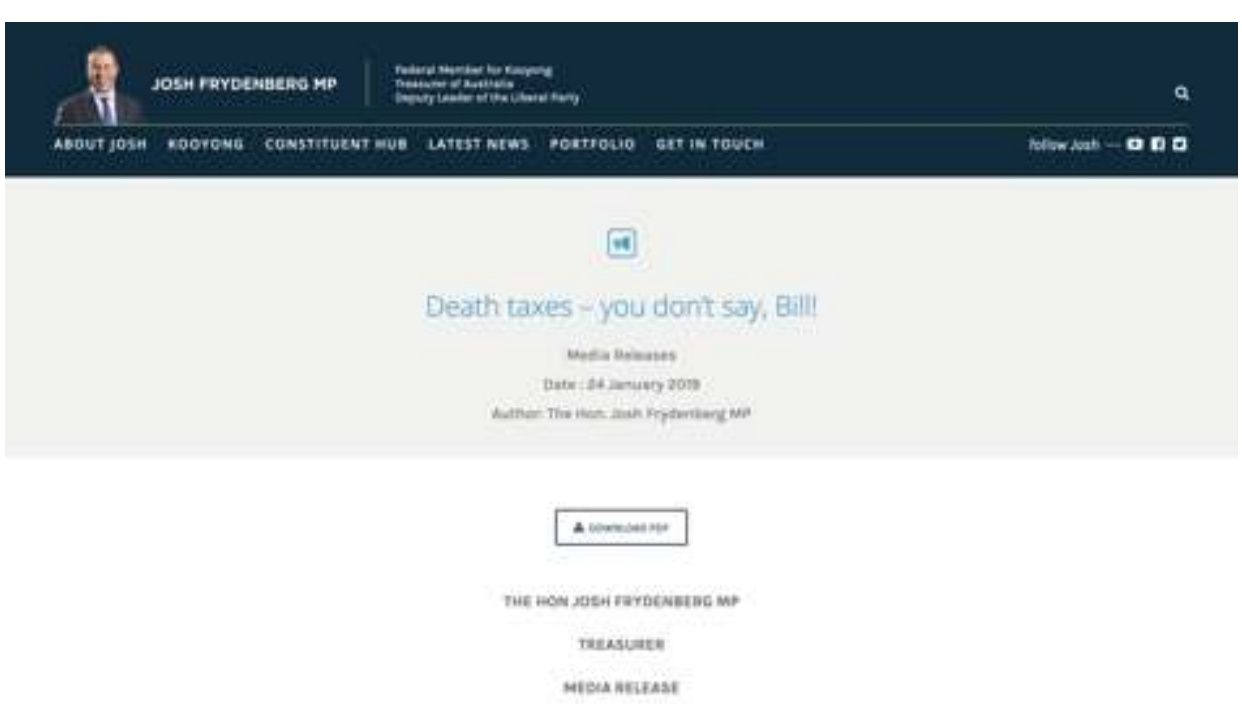

Figure 1. Josh Frydenberg Online media statement (24th January 2019).

The data collection for the research took place between 22nd April and 16th May 2019 and took the form of monitoring stories regarding Death Tax on Social Media platforms either in the form of collecting stories or searching hashtags such as \#deathtax. The posts were categories as being videos posted, articles or links shared via social media or the sharing of graphical pictures known as memes. The additional information that was collected was the views of video files, the number of likes per post, the comments that were made about the posts and the number of times the posts were shared.

The data collected is broken down into the following samples.

\begin{tabular}{|l|l|c|c|c|c|c|}
\hline & & Posts & Views & Likes & Comments & Shares \\
\hline $\begin{array}{l}\text { James Mcgarth } \\
\text { Liberal } \\
\begin{array}{l}\text { National Party } \\
\text { (LNP)) }\end{array}\end{array}$ & Videos & 1 & 10934 & 67 & 18 & 39 \\
\hline $\begin{array}{l}\text { George } \\
\text { Christensen } \\
\text { (LNP) }\end{array}$ & Article & 17 & $\begin{array}{c}\text { Not Applicable } \\
\text { (NA) }\end{array}$ & 3600 & 1444 & 3848 \\
\hline & Videos & 1 & 90730 & 44 & 28 & 17 \\
\hline & Memes & 5 & NA & 958 & 362 & 782 \\
\hline $\begin{array}{l}\text { Alex Hawke } \\
\text { (Liberal Party } \\
\text { (LP)) }\end{array}$ & Videos & 1 & 1400 & 79 & 40 & 24 \\
\hline & Articles & 1 & NA & 9 & 5 & 9 \\
\hline $\begin{array}{l}\text { Jane Hume (LP) } \\
\text { Matthew Fraser } \\
\text { (The Nationals } \\
\text { Party) }\end{array}$ & Articles & 1 & 25000 & 268 & 78 & 189 \\
\hline & Videos & 1 & NA & 55 & 23 & 26 \\
\hline & Meme & 1 & NA & 46 & 11 & 22 \\
\hline
\end{tabular}

Table 1. Death Tax Posts by Individual Politicians within the Coalition Parties. 


\begin{tabular}{|l|l|c|c|c|c|c|}
\hline & & Posts & Views & Likes & Comments & Shares \\
\hline Liberal Party & Videos & 3 & 221000 & 2371 & 1062 & 960 \\
\hline & Articles & 2 & NA & 3400 & 2031.00 & 2700.00 \\
\hline LNP (QLD) & Memes & 2 & NA & 1200 & 749 & 620 \\
\hline & Videos & 2 & 206000 & 376 & 404 & 275 \\
\hline $\begin{array}{l}\text { Country } \\
\text { Liberal Party } \\
\text { (NT) }\end{array}$ & Videos & 4 & 265000 & 48 & 2 & 39 \\
\hline & & Posts & Views & Likes & Comments & Shares \\
\hline & Total & 13 & 692000 & 7395 & 4248 & 4594 \\
\hline
\end{tabular}

Table 2. Death Tax Posts by Coalition Parties.

\begin{tabular}{|l|c|c|c|c|c|c|}
\hline & & Posts & Views & Likes & Comments & Shares \\
\hline $\begin{array}{l}\text { Pauline } \\
\text { Hanson - One } \\
\text { Nation }\end{array}$ & Videos & 1 & 187000 & 4100 & 2500 & 4400 \\
\hline $\begin{array}{l}\text { One Nation } \\
\text { Party }\end{array}$ & Articles & 1 & NA & 262 & 103 & 262 \\
\hline $\begin{array}{l}\text { Great } \\
\text { Australian } \\
\text { Party }\end{array}$ & Articles & 1 & NA & 219 & 141 & 496 \\
\hline & & Posts & Views & Likes & Comments & Shares \\
\hline & Total & 3 & 187000 & 4581 & 2744 & 5158 \\
\hline
\end{tabular}

Table 3. Death Tax Posts by Minor Political Parties.

\begin{tabular}{|c|c|c|c|c|}
\hline Posts & Views & Likes & Comments & Shares \\
\hline 46 & 1008564 & 17156 & 9019 & 14745 \\
\hline Ratio Per Post & 67238 & 477 & 251 & 410 \\
\hline
\end{tabular}

Table 4. Total of Death Tax Posts and impact.

\section{Discussion}

In terms of the Death Tax posts, the individual posts were by Australian Coalition politicians (members of the Liberal Party, National Party or Liberal / National Party (Queensland), Country Liberal Party (Northern Territory)) (see Table 1), the sample took the form of individual posts by Coalition politicians, apart from George Christensen (Liberal National Party, Queensland) who posted 17 items during the data collection period and had the greatest impact of the Coalition politicians. The Coalition Parties posted 13 posts (see Table 2) about the Death Tax and these took the form of videos and memes, the videos were very popular with around 692000 views of these videos. The Death Tax stories was also posted by minor parties (One Nation and the Great Australian Party) and the leader of the One Nation Party (Pauline Hanson) (see Table 3). The video by Pauline Hanson took the form of interviewing voters at a Tasmania Country Fair about the Death Tax item and was viewed by 187000 people (see Figure 2) and had the most views of all the videos posted on YouTube by the minor political parties. 


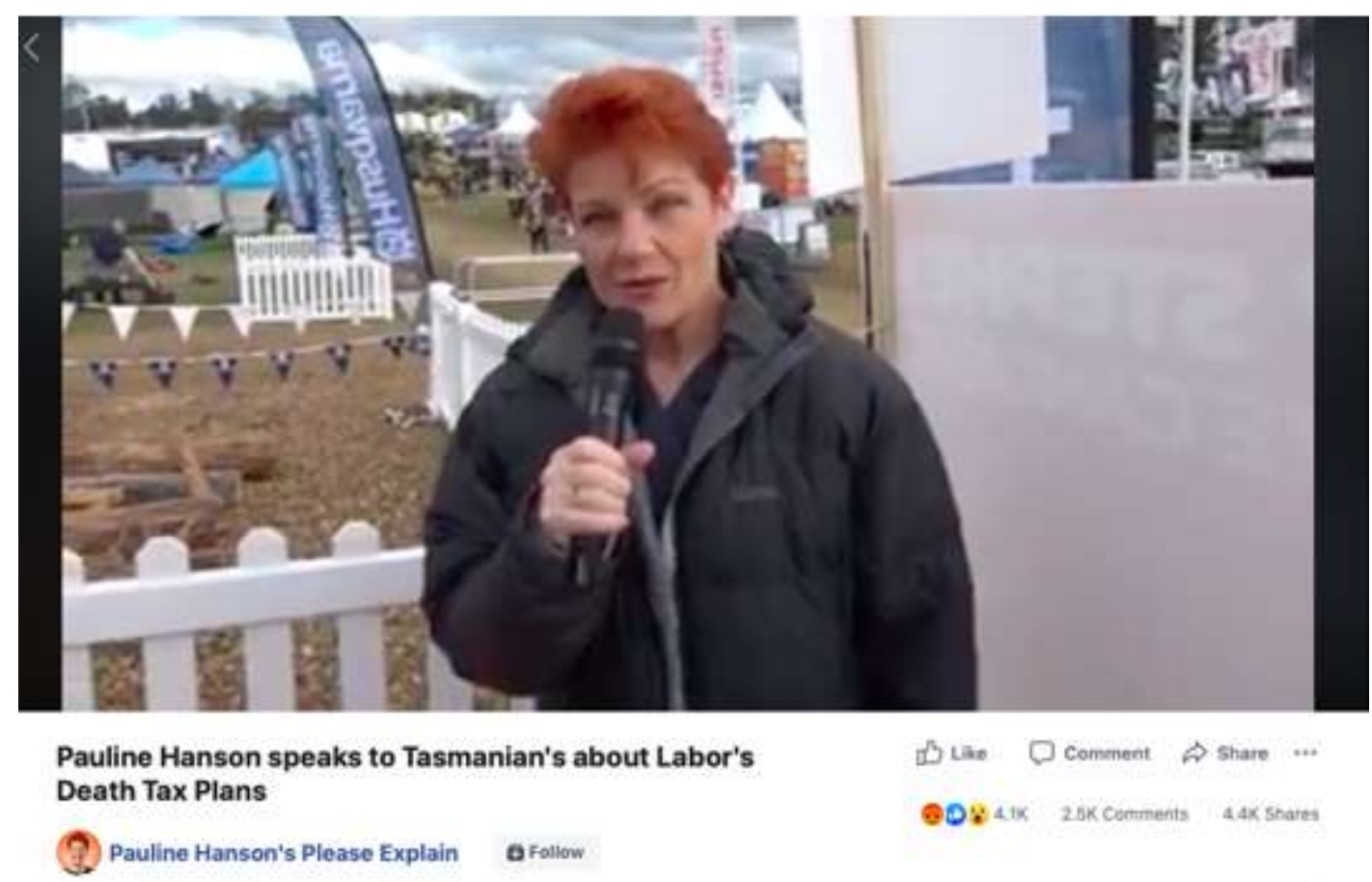

Figure 2. Pauline Hanson Interviews voters about Labor's Death Tax Plans (Note: the YouTube clip was removed after the general election finished).

In terms of the summaries of the different posts (see Table 4), the videos related to the Death Tax was viewed by over a million people and average view of each video (of the 15 videos) was 67238 views. In terms of the Death Tax posts, on average each post was liked 477 per post, an average of 251 comments per post were made and on average each post was shared 410 times. From the data collected and the assessment made, the Death Tax stories had a big impact upon social media users, in terms of their views of videos, liking of posts, comments made and sharing of posts especially with over one million views of the videos posted on Facebook or YouTube.

How did the Labor Party respond to the situation, "the Opposition Leader Bill Shorten has hit out at the Coalition for a case of "Fake News" being spread on social media, saying his opponents should be ashamed for mounting a scare campaign about a tax on inheritances" (Sydney Morning Herald, 2019a). The Labor Party asked Facebook, to remove the Death Tax content from the Facebook platform and the posts should be treated as Fake News (Sydney Morning Herald, 2019b), Facebook never removed the posts. In addition, the Labor Party ran online videos accusing the Coalition of introducing their own Death Taxes and also sharing information about the Death Tax situation via their website (Labor, 2019), this is shown in Figure 3. 


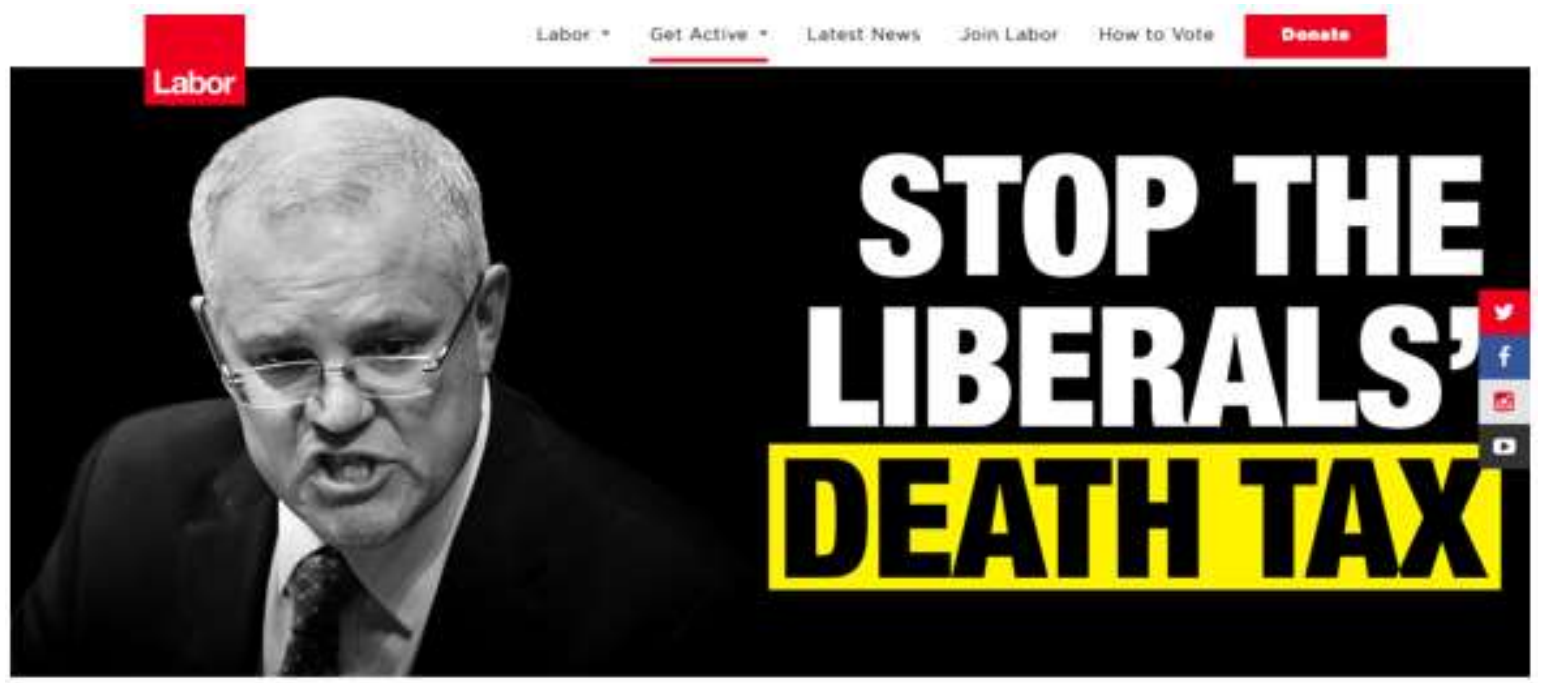

Figure 3. Labor Advertising against the Liberals Death Tax.

Using the French Government (French Government, 2018) definition of Fake News, the Death Tax story and information was maliciously published and disseminated by various methods on social media and the information had been fabricated and falsely attributed to third parties, in this case being the Labor Party.

But by using the more detailed United Kingdom Parliament (UK Government, 2018) definition of Fake News, as shown in Table 5 we can gain a greater understanding of how the Fake News was created and evaluated against the six Fake News criteria items.

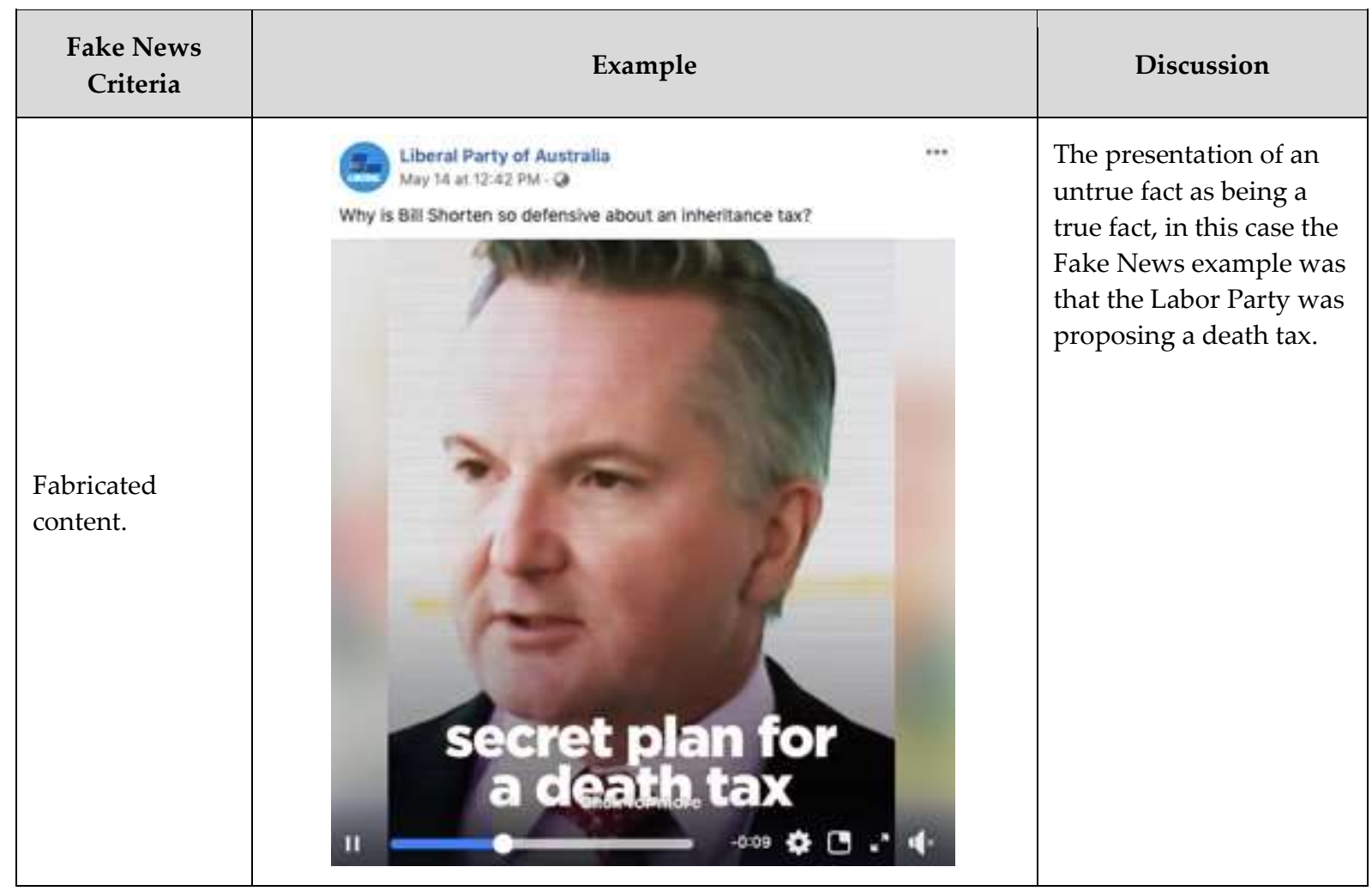




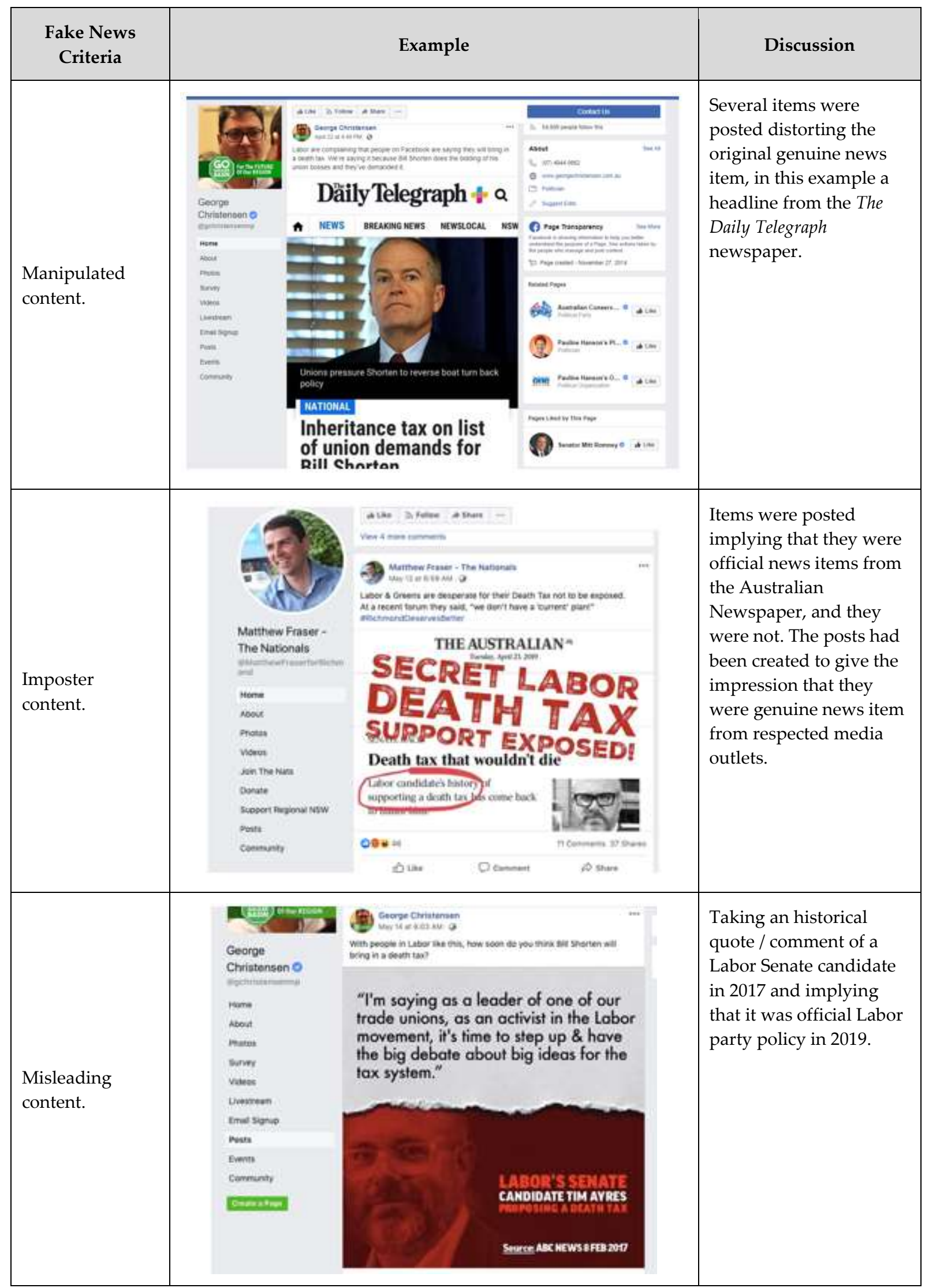




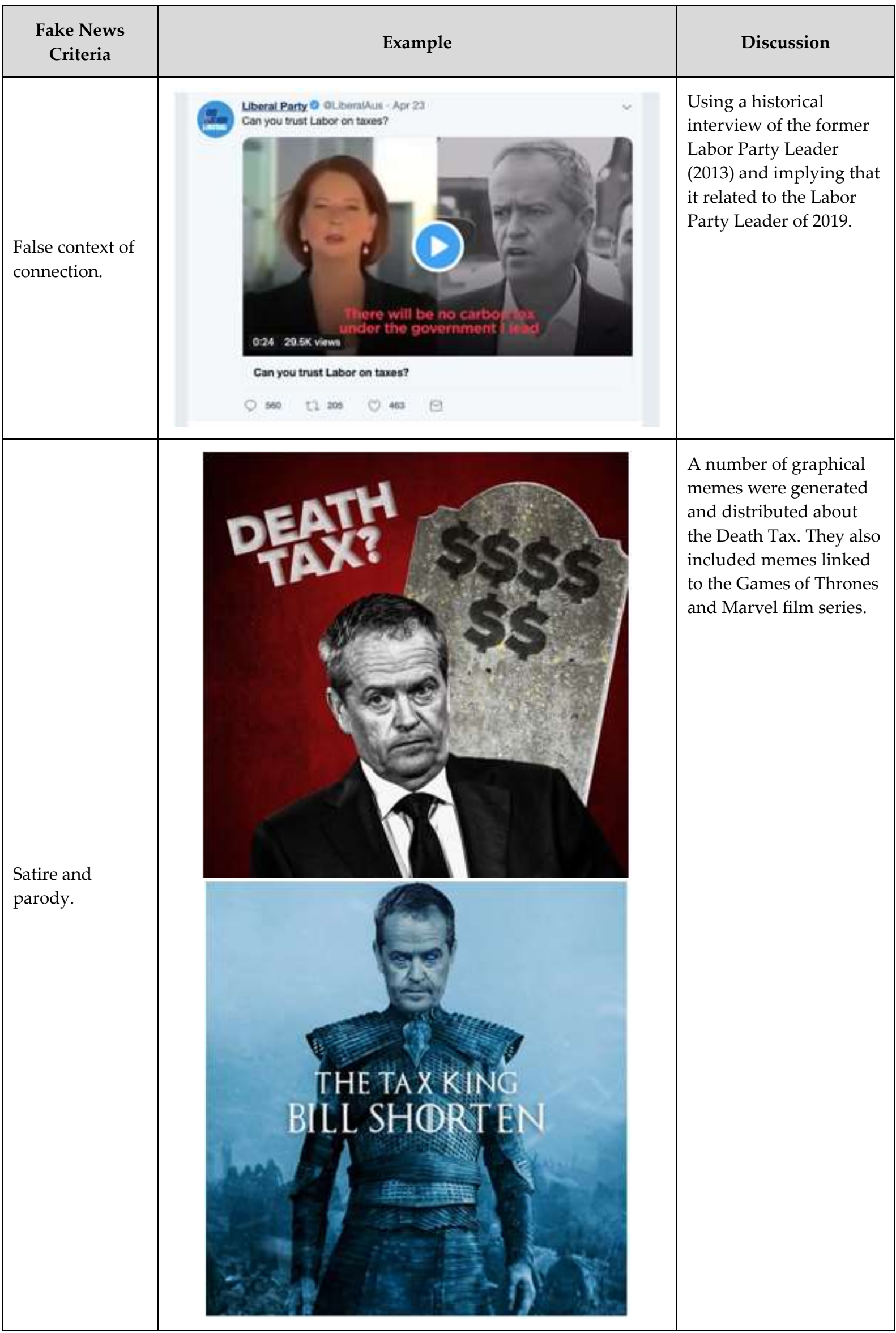

Table 5. Evaluation of Australian Fake News Case using the UK government criteria. 
Using the United Kingdom Parliament definition of Fake News, all six of the Fake News criteria were shown to have been meet. In terms of the original research question presented at the start of the paper "Was there any occurrence of Fake News during the Australian General Election in 2019", the paper has demonstrated that Fake News did occur during the Australian 2019 General Election.

\section{Conclusion}

As we have seen social media impacts all aspects of society from citizens to businesses but also political parties. We now see that all poltical parties use social media to engage with voters and this use of social media becomes key at election times to engage with voters and potential voters.

The paper has limitations, in terms of the social media data sample that was collected during the given time period and the analysis of the data sample that was collected. But the paper has made a major contrunition is terms of identifiying that there was a major example of Fake News during the Australian General Election in 2019. The paper shows that a Fake News incident relating to the Death Tax had occurred during the 2019 election, that associated video clips had been watched over a million times, that associated posts had over seventeen thousand likes, nine thousand comments had been made about the related posts and the Fake News clips had been reshared over fourteen thousand times with other social media users.

As discussed at the start of the paper, a key issue for individual politicians and political parties is whether they focus on making judgements and whether they act in an ethical manner. As identified in the paper during the 2019 Australian general election there were a number of political parties and individual politicians that did not act in an ethical manner.

When the research project started, the author was under the assumption that any Fake News generated during the Australian Election would be from overseas entities trying to influence the outcome of the Australian Election results and not Australian political parties and politicians generating Fake News.

\section{References}

ABC (Australian Broadcasting Corporation). (2019). Federal election 2019: Prime Minister Scott Morrison sets May 18 election date, https://www.abc.net.au/news/2019-04-11/primeminister-scott-morrison-calls-federal-election- may-18/10991614, accessed 10/6/19.

ASPI (Australian Strategic Policy Institute). (2018). Defining offensive cyber capabilities, URL: https://www.aspi.org.au/report/defining- offensive-cyber-capabilities, accessed 10/6/19.

Buckmaster, L. and Wils, T. (2019), Responding to Fake News, Australian Parliament Briefing Paper, Canberra, Australia.

Crilley, K. (2001). "Information warfare: new battle fields Terrorists, propaganda and the Internet”, In Aslib Proceedings vol. 53, no. 7, pp. 250-264. MCB UP Ltd.

French Government. (2018). Fake News: a bill to combat the manipulation of information https://www.gouvernement.fr/en/fake-news-a-bill-to-combat-the-manipulation-ofinformation, accessed 10/6/19. 
Frydeberg, J. (2019). Media Release - Death Taxes - You Don't Say, Bill!, URL: https://joshfrydenberg.com.au/wp-content/uploads/2019/01/Treasurer-Media-ReleaseDeath- taxes-you-dont-say-Bill.pdf, accessed 10/6/19.

Kaplan, A. M., \& Haenlein, M. (2010). Users of the world, unite! The challenges and opportunities of Social Media. Business Horizons, 53(1), 59-68. doi:10.1016/j.bushor.2009.09.003.

Labor Party. (2019). The facts about an inheritance tax, URL: https://www.alp.org.au/the_facts_about_an_inheritance_tax, accessed 10/6/19.

Sample, C, McAlaney, J and Thackray, H. (2018). A Cultural Exploration of the Social Media Manipulators, 17th European Conference of Cyber Warfare, Oslo, Norway.

Sydney Morning Herald. (2019a). 'It is a lie': Bill Shorten targets Liberals for death tax 'Fake News' on Facebook, URL: https://www.smh.com.au/federal-election-2019/it-is-a-lie-bill-shortentargets-liberals-for-death-tax-fake-news-on-facebook-20190420-p51fu6.html, accessed $10 / 6 / 19$.

Sydney Morning Herald. (2019b). 'Labor demands Facebook remove 'Fake News' posts about false death tax plans, URL: https://www.smh.com.au/federal-election-2019/labor-demandsfacebook-remove-fake-news-posts-about-false-death-tax-plans-20190419-p51fpk.html, accessed 10/6/19.

Taylor, P. M. (2013). Munitions of the Mind: A History of Propaganda. Manchester University Press, UK.

Thompson, D.F. (2019). Political Ethics. In International Encyclopedia of Ethics. Wiley Publishers, UK.

UK Parliament. (2018). Disinformation and 'Fake News': Interim Report, Fifth Report of Session 2017-19, London, UK.

UK Parliament. (2019). Disinformation and 'Fake News': Final Report, Fifth Report of Session 2017-19, London, UK

Waltzman, R. (2017). The Weaponization of Information, RAND, URL: https://www.rand.org/content/dam/rand/pubs/testimonies/CT400/CT473/RAND_CT47 3.pdf, accessed 10/11/19.

Copyright: (C 2020 Warren. This is an open-access article distributed under the terms of the Creative Commons Attribution-NonCommercial 3.0 Australia License, which permits noncommercial use, distribution, and reproduction in any medium, provided the original author and AJIS are credited.

doi: https://doi.org/10.3127/ajis.v24i0.2803 


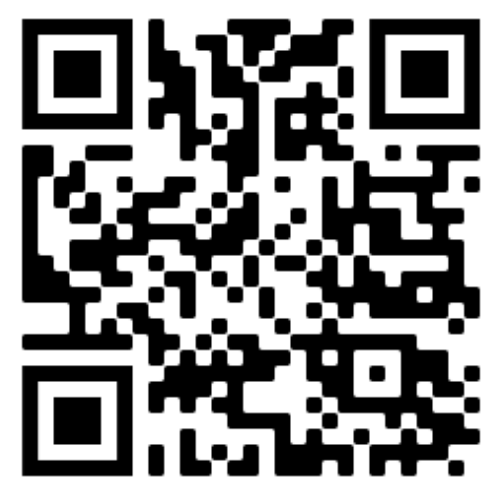

